\title{
A Study on Designing and Evaluating Multimedia Courseware in EST Teaching
}

\author{
Jifeng Cao \\ Changchun University of Science and Technology, Changchun, China
}

\begin{abstract}
English for science and technology(EST) teaching is different from normal English teaching mainly due to students' lack of contact with the discussed topics in real life. And the feasibility of taking use of multimedia technology in EST class has been mentioned by many scholars. However, there are few papers referring to the way to design multimedia courseware for EST class and how to assess the effect of the designed courseware. This paper aims at sharing author opinion and experience on principles and steps of designing and assessing multimedia courseware for EST class.
\end{abstract}

Index Terms-EST teaching, Multimedia technology, Designing and evaluating

\section{InTRODUCTION TO EST TEACHING AND MULTIMEDIA TECHNOLOGY}

As Xu Youzhi (2005) mentions in his book, "our age is an age of machines, electronics and computers. With the development of science and technology, scientists and engineers exchange their ideas, discoveries and inventions, collect information and data, interpret concepts and theories, comment on the latest scientific advances and write reports based on experimental procedures, etc. hence the need for economical, efficient and impersonal ways of expression: the English of science and technology". English for Science and Technology (henceforth EST) is a functional varying style. It is a scientific and technological register formed by scientists and technicians to meet the demands of scientific communication. It is a language used by the scientists and technicians in a special circumstance. And it would seem to be both an occupational and educational use of English: occupational when considering the needs of oilfield workers, engineers or computer programmers; educational (academic) when considering university students throughout the world studying physics, chemistry, math through the medium of English. EST learning concerns about the different aspect of this type of English such as its grammatical features, lexical features and semantic features, which necessarily increase the difficulty for learning it. Therefore necessary tools like multimedia are supposed to be used in the teaching for aid.

Multimedia technology, which is characterized by a combination of graphic, textual, audio and video functions, is superior to any other medium in its devastatingly huge mass of information, high speed of information exchanging and partaking of information resources, especially after the Internet comes out (Ahamad, 1985). Nevertheless, according to the author's investigation, the application of computer multimedia technology to the teaching of English for science and technology (henceforth EST) is still at an initial stage, which indicates the lagging in the teaching approach of EST as well. EST teaching requires an effective approach to present a great deal of authentic background information, which arouse learners' interest and establish a living background context. Undoubtedly, multimedia technology naturally becomes a good choice for language teaching. This is where the points of the paper lie in.

With the development of information technology, studies of the influences of learning model with multimedia application upon EST teaching are reasonable. Furthermore, the former researches on this aspect mostly focused on the theoretical principles or some teaching technologies, but not much has been done upon the practical functions, namely the effects of the concerned educational technology on the effect of the learners' study (Debski \& Levy, 1999). Especially in the aspect of the multimedia and network technology-aided English learning model, little has been done. The study is an empirical research on the effects of the Multimedia application upon English for science and technology Learning and teaching model especially upon the third-grade learners, including their beliefs and behavior. The research questions to be addressed in the study are the following:

1. To what degree do Chinese English majors master EST through traditional way of teaching?

2. To what degree do Chinese English majors master EST effectively through improved teaching model?

3. Does the use of multimedia application substantially improve the effect of class?

4. What is the students' attitude toward EST learning under different teaching model?

5. What is the relationship between the multimedia use and the EST learners' English achievements?

\section{Problems Facing EST Teaching and Feasibility of Applying Multimedia Technology in EST Teaching}

As for the problems facing EST teaching, which are different from normal English teaching, are mainly the two aspects below: a) students' failure in understanding the stylistic features of EST; there are quite a lot of differences between the stylistic features of EST and those of other type of article, leading to many difficulties for the students to understand; b) and students' difficulty in fully comprehending the text, probably due to the lack of contact with the 
topic in real life (Chapelle, 2001). For the EST is mainly about the scientific discoveries and inventions, new concepts, theories, comment on the latest scientific advances and reports based on experimental procedures, etc. those things mentioned above are comparatively difficult for English majors in china to understand. Secondly, the economical, efficient and impersonal ways of expression in the articles like mathematics, physics, chemistry, biology, psychology, and so on are quite different from what the Chinese English majors used to read. c) Compared with articles learned in other classes, the articles of EST seldom present interesting stories that can intrigue students. Simply, sometime students' feedback showed that EST class was boring (Hainline, 1987).

The problems mentioned above strongly suggest that EST should be taught in the way different from traditional one. Hence, here comes the following discussion about the feasibility of applying CALL in EST teaching.

There is a very old-fashioned question, that is, should multi-media computer be used to aid EST learning? The answer is becoming clearer ever since researchers began to reach the study about it.

There are various studies which have shown the value of using computer in foreign language learning and teaching, especially in reading. Pusack \& Otto (1997) investigated how reading comprehension can be facilitated with a multimedia application for language learning. They investigated the effects of a dynamic visual advance organizer on the macro level and the effects of multimedia annotations for single vocabulary items on the micro level. In addition, they examined the relationship between vocabulary acquisition and reading comprehension. From the results of their study can get the indications that the visual advance organizer does aid in overall comprehension and that annotations of vocabulary items consisting of both visual and verbal information assist more than verbal information only. Also, a moderate relation between vocabulary knowledge and reading comprehension was detected. Pusack \& Otto (1997) stated that the results support the dual coding theory and its extension to multimedia learning and lay emphasis on the significance of visual information in addition to verbal information to approve both top-down and bottom-up processing in reading in a foreign language.

In china, the classroom learning and teaching mainly constitutes three elements: teacher, students, and materials. Only when the environment presents appropriate conditions can learners achieve best. What can be called appropriate condition for learners? And how can we achieve the appropriate condition? Here comes the multimedia to rescue in this problem.

Among the special characteristics of multimedia, the promotion of autonomous learning is an important advantage. Learners who can take advantage of multimedia connections to explore explanations and peripheral information can somehow lower the teacher-centeredness of the classroom, for example, learner dependence on the teacher as the only source of information (Ruschoff, 2002). A well-formed multimedia database of materials can also assist those learners who lack skills in dictionary and library search.

As we mentioned above, there are a number of advantage of using multimedia in integrative CALL program. However, apart from those advantages there are also quite some disadvantages of the utilization of multimedia technology in integrative CALL (Tiene \& Ingram, 2001). And all of those defects must be elaborated for the teachers who want to use multimedia application in EST teaching so as to curb the teachers to overstate the advantages of multimedia application.

In first place, nowadays, we can't get courseware or programs from the market which is enough for EST teaching. Even there are some coursewares or multimedia program can be used in the teaching, shortly after the use the teachers can easily prove them a failure to be qualified for the teaching due to its improper organization of the multimedia resources in it.

Secondly, there is a deniable fact that most teacher in EST teaching are not able to design multimedia courseware by themselves even though they are in good training for how to organize the materials for the students to learn.

Thirdly, multimedia courseware itself is of some kind of defects which mainly due to their failure in integrating all necessary skills concerning integrative CALL. Put simply, for the training of listening and reading, they can be easily realized in the multimedia courseware. While multimedia fails to achieve the communication environment to some extent which can be of no pity (Tiene \& Ingram, 2001).

Fourthly, in terms of the evaluation function of multimedia technology, it's also of some defect. Simply, it can successively assess and judge the students' input by clicking the mouse or through the keyboard. However, the input in the form of voice or sound can be realized effectively.

\section{How to Take Use of Multimedia Technology to Design Courseware in EST Teaching}

Highly structured materials need to be available to cater to the needs of those learners with a strong dependence on teacher direction. However, to cater to the differentially rapid development in the direction of autonomy, it is also necessary to provide the means whereby learners can take more control if they feel capable of doing so. This can be achieved by selecting different learning materials by teachers, but it's better for the teacher to design the multimedia application directed to the EST study. In this chapter, we are going to have a detailed study about this.

Basically, there are two options for the teacher's use while making the multimedia application, that is, macromedia Authorware and macromedia director. In order to make the software for teaching, the teacher needs to learn either Authorware or director. In this case, the author recommends director for its powerful function. 
The newly released director offers several new features that enhance the capabilities of Macromedia Director and Shockwave movies. The main improvements are as follows:

1. Support for interactive three-dimensional (3D) graphics.

2. Enhancements to the Shockwave Multiuser Server and Xtra that enable server-side scripting, multithreading, and file access. Using server-side scripts can dramatically simplify your multiuser movies by placing most of the required logic on the server.

3. Support for Flash 5 and additions to Lingo that provide control over the new features of Flash 5 movies.

Before making the software, the maker needs to make sure that you have the following:

1. basic skills about how to work with a computer

2. macromedia director in your computer

3. Adequate material (images, sounds and so on) for the making of this software.

After learning the new improvements of Director, EST teachers can start making their own courseware. For making a qualified courseware, it usually involves the following ten steps: firstly, Set up the movie; secondly, Create cast member; thirdly, Import cast members; fourthly, Create sprites from cast members; fifthly, Create simple tweening animation; sixthly, Blend sprites; seventhly, Create frame-by-frame animation; eighthly, Attach behaviors to sprites; ninthly, Add sound; tenthly, Publish your movie in one step.

In the previous section, the reader can learn the basic skills of making a project. In this section, the main features of the software used in the study will be illustrated. The author of this thesis paid great effort in the designing of the software before it was employed in the study. In order to make it well-designed, the author made a wide range of survey of software with similar functions. Based on the guiding theory discussed above and the survey, the software was eventually designed and presented to the subjects after the author's half years' work. In the software, the author wants it bearing the following functions so as to improve the EST teaching.

1. Rich materials

2. Interactive function between computer and the user

3. Automatic study

4. Detailed analysis of stylistic features

In this software, rich material can be presented to the subjects in the form of both visual one and audio which, the designer believe, surely help subjects not only learn more background information but also understand the article better. The exercises are typical example to prove the strength of interactive function. The students can take the exercises for a form of testing. After they finish the tests, the software can give a accurate grade to the students. Another feature of the software is that it provides opportunities for the students to learn automatically either in class or after class. In addition, students can be divided into groups to discuss what they learned in the software. Another important feature of this software lies in its presentation of detailed analysis of the stylistic feature of the article, which, according to the survey before designing the software, never appeared in other software before.

\section{How to Evaluate the Courseware Designed for EST Course}

After using the courseware designed, we need to analyze the practicability of it. As to how to make the analysis, the author suggests the combination of test, questionnaire and interview. It involves the following steps:

Step 1: at the beginning of the study, the purpose of the study was fully elaborated to the students and a pre-test was done to the students in order to make contrast with the result of a post-test done at the end of the study.

Step 2: A Pilot study was conducted to make sure that the items in the Questionnaire are clear, suitable and enough, at the same time, to decide the Period of time needed for answering the questionnaire. After two rounds of revision, the questionnaire was administrated. And the Questionnaires were given to the subjects of different classes.

Step 3: The statistics of each section and each class were put into computer. With the help of SPSS or Microsoft Excel, the results were worked out for further analysis.

Step 4: In order to get further awareness of the subjects' attitudes towards EST learning under suggested multimedia teaching model, student volunteers were interviewed.

Step 5: The questionnaire result of two-group subjects' responses was analyzed. In addition, the comparison of effects of learning between the new teaching model and the traditional one was worked out for analysis.

Next will be one example for how to assess the courseware.

\section{A. Two Tests}

Before the application of multimedia courseware to the students, a test was held to get the average score of the students in terms of the relevant knowledge about EST learning. The purpose of the test is to discover whether there existed any difference in terms of the students' mastery of the EST language between the two groups. After the application of multimedia courseware to the students, the other test was held to see whether there is any effect on the students who take the application of multimedia courseware. The test is to find out whether there is any effect on the students who have attended the EST class with the application of multimedia courseware.

\section{B. A Questionnaire}


A questionnaire was designed to learn about students' attitude towards the application of multimedia courseware. The content of the questionnaire is made up of six parts as the followings:

Part A: questions concerning the students' opinion about EST learning

Part B: attitudes about EST learning with the application of multimedia courseware;

Part C: questions with regard to students' use of computers;

Part D: questions about the former and the suggested way of EST teaching;

Part E: beliefs on cooperative work with the application of multimedia courseware;

Part F: assessments of teacher's role.

\section{Interview}

After the administration and the initial analysis of the questionnaire data, a face-to-face interview was conducted, which centered on the items in the questionnaire. The interview with each subject was conducted in Chinese. Only twenty students and the teacher participated in the interview due to the limited time.

\section{Data Analysis Method}

The results were assessed by Microsoft Excel. Data analysis included two parts. In the first part, only percentage was calculated when the results of the questionnaire completed by all the subjects to show the overall tendency of the subjects' attitudes towards EST learning under two different teaching models. In the second parts, test was employed when comparison between two groups' subjects was made for clarity.

The qualitative data of interview were analyzed by organizing, summarizing and synthesizing so as to arrive at the results and conclusions of the research.

Data collection work was done in two different periods. Firstly, the pre-test was done at the beginning of the term; secondly, the post-test, questionnaire and the interview were done at the end of the semester after the application of the multimedia courseware. It should be an appropriate time as the subjects could provide more exact and objective comments on EST teaching.

\section{E. Procedures}

The First Period: before the application of multimedia courseware to the students, a test was held to get the average score of the students in terms of the relevant knowledge about EST learning. After the application of multimedia courseware to the students, the other test was held to see whether there is any effect on the students who take the application of multimedia courseware. After the test was held, the average score of both groups was worked out for the research. In the author's intention, if there is difference between the score of the two groups concerning the two tests held in different periods, there may be some effects of the application of multimedia courseware to the students. Otherwise, it will go the opposite direction.

The Second Period: The questionnaire was designed on the basis of the questions, such as, the students' opinions about EST learning; attitudes toward the application of multimedia courseware; questions with regard to students' use of computers; questions about the former and the suggested way of EST teaching; beliefs on cooperative learning with the application of multimedia courseware. The research was done in the classrooms. In that day, every student in the experiment got one sheet of paper with questions. In class, if the students have any question about the questionnaire, they can raise their hands. And then the teacher will come to their assistance. Because the aim of conducting the questionnaire is to learn about the students' understanding about the research and opinions about the application of multimedia courseware, the students were required to be extremely honest. As to the time limit in answering the question, the students are asked to take their time as they like before the end of that day to make sure the students have sufficient time in answer to the question.

The Third Period: In order to get more subjective information about the application of the courseware which can not be acquired through the analysis of the test and the questionnaire, the interview is conducted.

In this experiment, the students in both group are give the same period of time, that is, once a week. Under the condition that all of students are provided with the same EST topic and time limit, they were taught in different learning models, namely, the traditional model for the first group and the suggested cooperative model supported by the application of multimedia technology for the second group. In order to lower the influence caused by the teacher's ability in instructing and controlling the class, only one teacher was used to be responsible for both the first group and the second group. Thus the influence caused by the teacher is reduced to the lowest point.

As for the concrete way of teaching, the way in the first group extremely follows the traditional one. For example, the teacher is supposed to require the students to preview the text before the class begins. In class, the students are asked to read the text aloud, to translate the text part by part and to summarize the idea of each part and the whole text. Of course, the teacher is supposed to help the students when they have difficulties in understanding the meaning of specific word and that of the text. In addition, after finishing the study of one unit, the students will take part in a test to check the effects of study.

As far as the second group is concerned, the suggested cooperative teaching model is applied to the EST class. As is mentioned in the previous chapter, the multimedia courseware is designed for the application of the cooperative teaching model in the EST class for group two. In the multimedia courseware, all kinds of media are adopted, such as, 
text, graphics, sound, movie, hypermedia and multimedia. There are five parts concerning the contents, namely, pre-reading, text analysis, stylistic features, exercise and reference. In the part of pre-reading, the students are divided into six groups for discussions on the basis of the text. In the part of text analysis, the explanations of difficult words, translation script, and the audio material of the text are integrated in this part. As for stylistic features, detailed illustration and typical example are presented to the students. In the part of exercise, two types of exercise, namely, blank filling and multiple choices, are incorporated. Finally, in the part of reference, rich materials in the form of text, graphics and video program are used in the assistance of the understanding for the students. In short, for the second group, a typical cooperative teaching and learning model is set up with the help of multimedia technology.

\section{F. Results Analyses of the Test Scores}

As mentioned above, there two tests carried out during the process of research. After the texts were finished, the average scores of students in the two groups were worked out to search for any possible differences existing between the two groups of data. The result is presented in the following table.

TABLE 1

N: NUMBER A: AVERAGE SCORE SD: STANDARD DEVIATION

N: NUMBER A: AVERAGE SCORE SD: STANDARD DEVIATION
\begin{tabular}{|l|l|l|l|l|l|l|}
\hline \multicolumn{1}{|l|}{ The experimental class } & \multicolumn{3}{l|}{ The control class } \\
\hline boys & N & A & SD & N & A & SD \\
\hline First test & 9 & 81.06 & 18.96 & 8 & 81.33 & 20.66 \\
\hline Second test & 9 & 89.35 & 17.62 & 8 & 83.54 & 27.48 \\
\hline girls & N & A & SD & N & A & SD \\
\hline First test & 48 & 84.23 & 19.23 & 49 & 84.68 & 24.75 \\
\hline Second test & 48 & 91.46 & 15.88 & 49 & 85.72 & 28.36 \\
\hline
\end{tabular}

Based on the results of the test score, the following conclusion can be drawn, that is, the students' average score of the second test in the experiment class is higher compared with that of the first test. This proves, to a certain degree, the cooperative way of EST learning and multimedia application help students' study. And the following analysis of the questionnaire will present us with more explanation.

\section{G. Results Analyses of the Questionnaire}

In the middle of the research, a questionnaire is conducted to the students. As mentioned above, the contents of the questionnaire mainly embrace six parts, namely, the students' opinions about EST learning; attitudes toward the application of multimedia courseware; questions with regard to students' use of computers; questions about the former and the suggested way of EST teaching; beliefs on cooperative learning with the application of multimedia courseware. In the author's opinion, the investigation of the students' perspective to the above six aspects will surely help the analysis about the effects of the application of multimedia technology.

The following table is a sample extracted from the analysis of the questionnaire, which show s the author way of analyzing the results and can also give us a clear image about the students' opinions of the follow aspects.

TABLE 2.

STUDENTS' ATTITUDE TOWARDS THE MULTIMEDIA TECHNOLOGY APPLICATION IN EST LEARNING

\begin{tabular}{|c|c|c|c|c|}
\hline Question No. & question & choice & No. of responses & percentage \\
\hline \multirow[t]{4}{*}{2} & \multirow{4}{*}{$\begin{array}{l}\text { In your opinion, multimedia } \\
\text { technology application in EST } \\
\text { learning is }\end{array}$} & unnecessary & 5 & 4.31 \\
\hline & & Not so necessary & 12 & 10.34 \\
\hline & & necessary & 76 & 65.52 \\
\hline & & Very necessary & 23 & 19.85 \\
\hline \multirow[t]{5}{*}{5} & \multirow{5}{*}{$\begin{array}{l}\text { You the teacher utilize } \\
\text { multimedia in EST class. }\end{array}$} & dislike & 6 & 5.17 \\
\hline & & Don't like very much & 11 & 9.48 \\
\hline & & like & 35 & 30.17 \\
\hline & & Really like & 49 & 42.24 \\
\hline & & Extremely like & 15 & 12.94 \\
\hline \multirow[t]{5}{*}{6} & \multirow{5}{*}{$\begin{array}{l}\text { To what effect does } \\
\text { multimedia courseware assist } \\
\text { EST learning in your opinion? }\end{array}$} & bad & 3 & 2.59 \\
\hline & & Not so bad & 16 & 13.79 \\
\hline & & good & 40 & 34.48 \\
\hline & & Very good & 48 & 41.38 \\
\hline & & excellent & 9 & 7.76 \\
\hline
\end{tabular}

From the sample we can see the positive effects of the use of multimedia technology.

According to the results of the questionnaire, there is an amazing agreement concerning the use of computer. The fact is that all the students can have access to the use of computer in the normal English learning. The second discovery is that all the students in the second group show great interests in the use of multimedia application. Furthermore, all of them stand up for the use of the application of multimedia courseware. Most (92\%) of the students tick the choice of necessary or very necessary in terms of use of the courseware.. The third discovery is that $70 \%$ of the students consider the effects of the application of multimedia courseware are positive. More discoveries will be discussion in the following part and the part of conclusion. 


\section{H. Results Analysis of the Interview}

The purpose of conducting the interview is to get more subjective information about the application of the courseware which can not be acquired through the analysis of the test and the questionnaire. For example, as for the students' impression, it is quite difficult to get detailed information from the test and questionnaire. Or in terms of the difficulties of learning EST, they can not be shown through the first two devices used before the interview was conducted. The design of the interview is on the guidance of compensating what has been left in the tests and questionnaires.

The following table shows most of the questions delivered to the students during the process of interviewing.

\begin{tabular}{|l|}
\hline 1. What's your impression of the software used in the study? \\
\hline 2. Can you name some strong points of the software? \\
\hline 3. List some weak points of the software. \\
\hline 4. What's the most important effect of the software upon your EST learning? \\
\hline 5. List some difficulties in learning EST. \\
\hline $\begin{array}{l}\text { 6. Do you think the part of discussion plays very important role in class concerning the learning of EST? And } \\
\text { support your opinion. }\end{array}$ \\
\hline
\end{tabular}

According to the interview, the author got better understanding of students' points of view of EST learning with application of multimedia courseware in this study. Generally speaking, most students think EST is difficult compared with other English course. Their lack of experience is the main reason for the difficulties in learning EST. therefore, the visual materials presented in the multimedia application contribute a lot to better understanding of the article in that they provide real-life environment. In addition, the testing system in the software ensures their prompt awareness of their weak points in the understanding of the test. On the other hand, some students complain that the explanation of stylistic feature of the article is not adequate and this part should be strengthened. On balance, the students' attitude toward the teaching model with multimedia application is positive, since most of them admit that it does help their studies.

\section{CONCLUSION}

The feasibility of applying computer multimedia technology to teaching activities of EST is analyzed. As we know, the video programs are everywhere. If the teacher who teaches EST is not capable of designing multimedia courseware, he may combine several programs into a perfect one. But a high quality courseware for EST class is more than that. The author still stresses the importance on taking use of multimedia technology to make proper multimedia courseware for EST class by themselves. The convenience in the application of multimedia courseware is seen by every teacher.

The purpose of the paper is to figure out both a proper way to design EST courseware and an appropriate method to assess the effect of multimedia application in EST teaching. The designing process is fully illustrated in the paper for the reference of the peers. And a detailed description on the author's suggestion of assessing the effect of multimedia courseware for EST class was made aiming at sharing the author's experience and getting feedback from the peers. The author believes more accurate data should be obtained for the study and further study of the similar subjects need to be made from different aspects.

\section{REFERENCES}

[1] Ahamad,K,L. (1985). Computers Language Learning and Language Teaching. Cambridge: Cambridge University Press.

[2] Chapelle, C. A. (2001). Computer Applications in Second Language Acquisition: Foundations for Teaching, Testing and Research. Cambridge: Cambridge University Press.

[3] Debski, R. \& M,. Levy. (1999). WORLDCALL---Global Perspectives on Computer-Assisted Language Learning. Netherlands: Swets \& Zeitlinger.

[4] Hainline, D. (1987). New Developments in Computer-assisted Instruction. New York: Nichols Publishing Company.

[5] Ruschoff, B. (2002). Languages. Tokyo: Springer, (3):523-539.

[6] Pusack, P. J. \& S. K, Otto. (1997). Taking Control of Multimedia. Chicago: National Textbook Company.

[7] Tiene, D. \& A, Ingram. (2001). Exploring Current Issues in Educational Technology. New York: McGraw-Hill Companies.

[8] Xu Youzhi. (2005). A Course to English Stylistics. Beijing: Higher Education Press.

Jifeng Cao was born in Panjin, Liaoning Province, China on September 5th, 1978, who has got a degree of Master of Arts in foreign linguistics and applied linguistics from Changchun University of Science and Technology, Changchun, Jilin Province, China in 2009 .

As a Lecturer, he teaches English for science and technology for the English major at School of Foreign Languages, Changchun University of Science and Technology. Two published articles are as follows: [1] Should the Basic verbs "get" and "put" be Learned First for College Students in Their Spoken English Class? (Global Academic Research Association Limited, Journal of Culture \& International Languages 2013); [2] Will Interaction between Teacher and Students Affect Students' Attitudes toward EST Learning? (Global Academic Research Association Limited, Journal of EFL Learning and Teaching 2013). Previous research interests are Linguistics. At present he focuses on ESP teaching. 